\title{
UK introduces 'research levy' on health care spending
}

London. Britain's Department of Health is to introduce a radical new system for funding health-related research, based on the distribution of a 'research levy' - currently estimated at just over one per cent - raised on money allocated to local health authorities for providing health care.

The estimated $£ 340$ million spent on research and development (R\&D) every year by Britain's National Health Service (NHS) is distributed in a variety of ways, including lump sum grants allocated to teaching hospitals through the Service Increment for Teaching and Research (SIFTR).

The government is worried that there is often little accountability for the way the money is

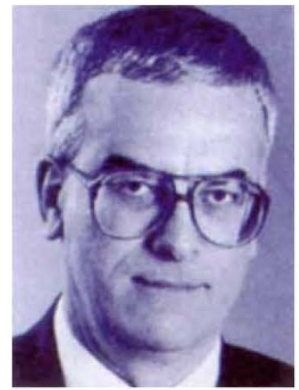

Culyer: arrangements 'in need of change'. spent. Others are increasingly concerned that research funding is being squeezed out by the short-term approach of the 'internal market' imposed on the NHS by successive Conservative administrations (see Nature 369, 514; 1994).

The new approach seeks to address both concerns through a system of 'managed competition' for research funds. Integrating all health research spending into a single funding stream will, says the government, help to ensure that funds are not diverted to other purposes. It will also require clinicians seeking backing for research projects to accept tighter scrutiny of both the scientific validity of proposals and the potential value of (and cost of applying) their results.

"This is an important new way of allocating our R\&D funds," says Michael Peckham, chief scientist at the Department of Health. "I see it as a real prototype of the way in which other countries could organize their [health-related] research by the side of their health systems, and not snarled up in them."

The reforms are based on the recommendations of a task force set up by the Department of Health to look at the support of R\&D in the NHS, and chaired by Anthony Culyer, professor of medical economics at the University of York.

The task force's report, based on written submissions from almost 200 institutions and professional organizations, as well as the work of three subgroups, paints a highly critical picture, reinforcing claims that even high quality research (for example, largescale clinical trials) is threatened by recent NHS reforms.

In line with the government's view that responsibility for spending decisions should be devolved to local authorities acting as the 'purchasers' of health care, some of those consulted proposed that research spending should be treated in the same way.

But the Culyer committee rejected such arguments, pointing out that research is carried out for "the common good" of the NHS. It suggested the introduction of a "common services levy" on all purchasers of health care, claiming that this would "symbolize common ownership of spending plans".

In releasing the committee's report last week, the Secretary of Health, Mrs Virginia Bottomley, said that the government had accepted its recommendation of uniting all NHS research spending into a single funding stream in order to secure "better targeting, management and accountability". Such spending represents about 1.1 per cent of the NHS's total budget, although the government has already committed itself to reaching an eventual target of 1.5 per cent.

Detailed discussions will soon begin between the department and the various bodies carrying out health-related research - ranging from university teaching hospitals to pharmaceutical companies that use NHS facilities for clinical trials of new drugs on how the new system will be put into effect, and what interim arrangements are needed to ensure a smooth transition.

The negotiations will not be easy, particularly as some are unlikely to welcome the new arrangements. University teaching hospitals, for example, had hoped to retain their control over funds through the SIFTR arrangements.

At the same time, the government is planning to discuss with Britain's three higher education funding councils ways in which the grading exercises already being applied to university departments can be extended to the research activities of all teaching hospitals.

Although medical charities - as well as the Medical Research Council (see right) have welcomed the extent to which the government appears to have adopted the main thrust of the Culyer report, namely that research funds need special protection within the new-style NHS, both are reserving their final judgement until they have seen how the new system is put into practice.

But Peckham's apparent success in persuading his political bosses that research spending requires protection within the NHS's market economy is said to have the backing of research managers in the pharmaceutical industry. These point out that the government's commitment to a centralized research strategy is similar to that of many of their own companies. David Dickson

\section{Health service to limit support for MRC-led trials?}

London. Proposed changes in the way in which the British government finances health-related research (see left) will open a new chapter in the somewhat bumpy relationship between the National Health Service (NHS) and the Medical Research Council (MRC), the UK's main source of funds for basic biomedical research.

In particular, according to Michael Peckham, formerly director of the Royal Postgraduate Medical School and now the Department of Health's chief scientist, the NHS will be less willing than in the past to offer itself automatically as a testbed for trials of techniques based on new discoveries made in MRC laboratories.

Under a 'concordat' signed with the MRC in 1992, the health departments promise to provide "the necessary service support for that research supported by MRC funds". But the task force chaired by Anthony Culyer says that this commitment is "too open-ended", as the NHS can devote only a finite sum to providing support for research and development (R\&D) projects. "It should not be obliged to support new MRC R\&D if it has good reason to believe that it has a better use for its money," the task force says.

Peckham describes the concordat as "in general a great success", but admits that "there have been problems". If a new trial is proposed on the basis of promising scientific results, he says, "we have to be able to ask whether it addresses what we consider to be an important problem, how much it is going to cost, and the likely benefit to the NHS," he says.

MRC officials have in general welcomed the planned new funding system, but are wary both of the likely impact of the extra administrative demands (for example for more peer review of proposals) and of pressures on NHS funding which could limit opportunities for longterm research projects into promising new treatments.

The MRC concordat, itself the result of a debate initiated by the Rothschild Report of 1972 over the role of the MRC as a 'contractor' meeting the needs of the health service as a 'customer', is due for renewal next year. Both sides accept the need for rewording, but negotiations may not be straightforward.

Peckham argues that "there needs to be a realistic understanding of what the NHS can sustain". The MRC wants to avoid a situation in which health departments become pre-occupied with meeting short-term goals at the price of longterm investment.

D. D. 